\title{
Trish Reid (éd.), Contemporary Scottish Plays
}

Londres, Bloomsbury, 2014, 354 p.

\section{Danièle Berton-Charrière}

\section{(2) OpenEdition}

Journals

Édition électronique

URL : http://journals.openedition.org/etudesecossaises/1035

DOI : 10.4000/etudesecossaises.1035

ISSN : 1969-6337

Éditeur

UGA Éditions/Université Grenoble Alpes

Édition imprimée

Date de publication : 25 avril 2015

Pagination : 194-197

ISBN : 978-2-84310-296-7

ISSN : 1240-1439

Référence électronique

Danièle Berton-Charrière, "Trish Reid (éd.), Contemporary Scottish Plays », Études écossaises [En ligne], 17 | 2015, mis en ligne le 25 avril 2016, consulté le 16 mars 2021. URL : http://

journals.openedition.org/etudesecossaises/1035; DOI : https://doi.org/10.4000/etudesecossaises. 1035

(c) Études écossaises 
Le livre de C. Roncato illustre avec beaucoup de clarté l'œuvre foisonnante de K. White et l'auteur a d'autant plus de mérite qu'il parvient à en rendre compte dans un ouvrage relativement bref mais très précis. Il est cependant une notion qui ne semble pas effleurée (volontairement?) — et peut-être que K. White lui-même récuserait — : l'idéologie de l'écologie, ou du moins la branche de cette mouvance qui récuse la modernité, le progrès et la croissance. Mais il s'agit là d'une piste différente (et peut-être fausse) que d'autres fervents de la poésie de White auront tout le temps d'explorer.

\section{Danièle Berton-Charrière}

Université Blaise Pascal-Clermont-Ferrand 2

Trish Reid (éd.), Contemporary Scottish Plays, Londres, Bloomsbury, 2014, 354 pages, £17.99

Dans ce recueil rédigé en anglais sont rassemblées cinq pièces écrites par des dramaturges écossais contemporains, éditées par Trish Reid : Caledonia de Alistair Beaton (création 2010), Bullet Catch de Rob Drummond (création 2009), The Artist Man and Mother Woman de Morna Pearson (création 2012), Narrative by Anthony Neilson (création 2013), Rantin de Kieran Hurley (création 2013).

Très bien documenté, clair et pédagogique, l'ouvrage comprend aussi un rappel chronologique de faits socio-politiques ayant marqué le théâtre, une introduction générale et critique qui donne les grandes lignes et les clés de chaque œuvre, ainsi que des micro analyses informatives précieuses. Ces repères ouvrent des axes d'étude qui augmentent les points de vue et montrent à quel point ces drames sont historiques, dans le sens où la réalité extra-contextuelle s'y trouve référencée de façon analogique, soit subtile et symbolique, soit par rappel factuel d'un événementiel qui fort habilement met le présent en abyme, comme l'expédition Darien de 1698, tenue comme la tentative catastrophique d'un colonialisme écossais (Caledonia) : «Fifth MP. (warming at the idea) A Scottish colony. 'Tis a bold idea. / Second MP. It may be worth... considering. / First MP. Aye, after all Paterson, we're men of the world. We're not against earning the odd shilling. / Paterson. Yes, and when the sands of history are shifting, that's when a man of the world can make a fortune.» (Caledonia, p. 17) 
Les chansons $\mathrm{n}^{\circ} 2$ Trade Begets Trade (p. 17), $\mathrm{n}^{\circ} 3$ (reprise p. 24) et $\mathrm{n}^{\circ} 4$ When You've Found a Bank (p. 25) illustrent, de manière enlevée et satirique, cette philosophie du profit et elles trouvent leur apogée dans la $\mathrm{n}^{\circ} 5$ The International Language : «Everybody speaks the language of money / It's the international language.» (p. 30) Toute ressemblance avec nos temps de crise et de krach troublés ne saurait être pure coïncidence.

Universitaire en poste à Londres — à Kingston University — Trish Reid est aussi actrice, chanteuse et musicienne. Sa recherche porte sur le théâtre écossais contemporain, et tout particulièrement sur comment se façonnent et se révèlent ses diverses identités sur la scène et dans le jeu, ainsi que par le truchement du véhicule langagier dans ses normes et ses socio- et géo-lectes. Son choix de textes est révélateur de ses propres centres d'intérêt et de l'évolution d'un théâtre qui a su s'imprégner de la tradition populaire poétique et musicale (ballades, pantomime... entre autres) tout en menant une réflexion sur les problèmes de notre époque. Dans un texte polyphonique comme Narrative, l'écriture se veut métadramatique et métathéâtrale. Au fil de rencontres qui envahissent le plateau de leur simultanéité atypique et de leurs discours presque trop simples, Neilson réécrit et repousse sans cesse les limites de l'écriture théâtrale, dans une débauche d'informations qui s'entremêlent dans les dialogues, les didascalies et dans l'accumulation des technologies à sa portée (film, vidéo, internet et YouTube dûment référencé). Ce théâtre s'affirme comme celui de son temps, comme maître de ses outils et comme en prise directe avec les événements et le public. Interactif, jouant avec les ouvertures et les surprises générées par le spectacle live («live entertainment», p. 118), il offre une certaine liberté de choix aux spectateurs et aux metteurs en scène. Drummond précise : «It should be stressed that each assistant was selected without preordainment from the theatre audience during the performance.» (Bullet Catch, p. 118) Une dose d'incertitude et de hasard s'immisce dans le spectacle et, entre crochets, le dramaturge raconte aussi quelques incidents qui sont arrivés au cours des représentations. Une didascalie du prologue de Narrative indique : "(The other four characters improvise their scenes concurrently now-the lines that follow are only a guideline and can be used or not. They may take the scenes in whichever direction they wish. Do not attempt at delineate the scenes - the audience must choose which to follow, but allow Barney to be heard until established.) (Narrative, p. 226).

Clin d'œil aux années 1970, ce théâtre est technique et inventif : improvisation, implication du public, contes, danses, chants et l'esprit du ceilidh... réverbèrent certaines formes et expériences de troupes sans cesse en tournées pour distraire les gens, d'un village à l'autre, les traditions et culture «folk». Dans son introduction, Hurley détaille l'entrée des uns et des autres dans son spectacle. L'ambiance est conviviale et 
familiale comme autrefois : "As the audience enter we are playing some tunes from the hi-fi. Chatting, getting a drink. We're setting up the space. Towards the end of this we'll encourage the audience to fill up their drinks and go for a pee and stuff. When it is time to start we open with a song. » (p. 311)

Dans ce type de théâtre, les formes sémiotiques enchâssées sont variées, divertissantes et structurantes. De Beaton («lyrics [...] some based on ballads of the time», c'est-à-dire le XVII ${ }^{\mathrm{e}}$ siècle, Caledonia, p. 3) à Neilson (Narrative), la palette musicale est large. Robert Burns y a sa place dans un arrangement de Gav Prentice dans Rantin (p. 352-353). Ce spectacle que Hurley qualifie de ceilidh-play — pour reprendre le néologisme de John McGrath - est un collage («a collection of fragments», p. 312) où se combinent des histoires et des chansons, des dialogues et des didascalies, est auto-réflexif. Il se commente, se recompose et se réécrit en scène live dans une revisite du Cogito ergo sum; ses métadiscours sont diégèse et exégèse.

Le théâtre écossais regarde le passé sans nostalgie lacrymale et s'en nourrit. Il regarde le futur sans peur et s'en réjouit. Il regarde enfin son propre présent sans condescendance avec un appétit infini. Sa réflexion est existentialiste, technologique et artistique.

Ces cinq pièces savent mêler humour, satire, tragique et sordide. De façon directe ou anamorphique, elles rendent compte d'une nation qui s'analyse, qui envisage son avenir et dévisage l'Autre, invasif, omnipotent et méprisant, au moment même où son devenir est mis à la question et remis en question : le référendum ne saurait être étranger à l'affaire.

The Artist Man and Mother Woman, de Morna Pearson met en scène Geoffrey, un professeur d'arts plastiques décalé, maintenu par sa mère dans une innocence puérile malsaine et dangereuse. Son portrait méchamment drôle déroute autant que déconcertent les relations dysfonctionnelles, insolites et abusives, qui mettent ce personnage en porte-àfaux avec Autrui. Morna Pearson dramatise des rapports mère-enfant, dominant-dominé, prédateur-proie, amis ou amants pervertis, au travers d'étranges duos. Elle montre comment chacun définit sa propre frontière entre l'amitié et l'amour, entre la gentillesse et le harcèlement, entre le fusionnel et la possessivité dévorante jusqu'à la folie. Surprotégé par Edie, mère omnipotente et quasi incestueuse, soumis à des tensions qui lui sont insupportables, Geoffrey tente en vain de perdre sa naïveté virginale et de couper le cordon ombilical. Leur «couple» exclusif est pathologique et mortifère; il les entraîne dans un enfermement liberticide.

Gette pièce rend compte de relations beckettiennes sur un ton qui mêle comique et malaise. Bien que le sujet puise dans le fonds tragique classique, les maladresses, la naïveté et la candeur du personnage central 
- archétype keatonien - le mâtinent d'un burlesque qui plonge dans l'horreur. Le spectateur hésite entre le rire, les larmes et le dégoût.

Les personnages s'expriment ici en Doric. Outre la contextualisation diégétique que procure ce dialecte du nord-est de l'Écosse, le choix linguistique amplifie le sentiment d'intimité et de promiscuité. L'impression d'appartenance à une communauté définie par son mode langagier ne semble pas se poser comme une revendication politique intradiégétique. Les auteurs qui en font usage affirment néanmoins leur identité au travers du décalage, de l'écart à la norme, quelle qu'elle soit (anglaise et/ ou écossaise).

Contemporary Scottish Plays édité par Trish Reid se révèle comme un cliché instantané — nécessairement partiel mais tout à fait représentatif du théâtre écossais qui se renouvelle sans cesse sans toutefois renier ses sources et ses influences. 